\title{
MARINE CONSERVATION AND MANAGEMENT AT SOUTH GEORGIA AND THE SOUTH SANDWICH ISLANDS
}

\author{
by L. F. Sahores
}

\begin{abstract}
Sahores, L.F. 2007 (23:xi): Marine conservation and management at South Georgia and the South Sandwich Islands. Papers and Proceedings of the Royal Society of Tasmania 141(1): 19-22. https://doi.org/10.26749/rstpp.141.1.19 ISSN 0080-4703. Consulado General de Argentina, Level 20, 44 Market Street, Sydney, NSW 2000, Australia.
\end{abstract}

South Georgia and the South Sandwich archipelagoes fall within the scope of SCAR (Scientific Committee on Antarctic Research) and CCAMLR (Convention for the Conservation of Antarctic Marine Living Resources). From the early twentieth century to the present Argentina has proposed and supported international agreements and conventions to regulate the harvesting of marine biota, and to promote marine conservation. Adherence to CCAMLR is required by Argentine law.

Key Words: sub-Antarctic, South Georgia, South Sandwich Islands, marine conservation, fisheries management, CCAMLR Convention.

The South Georgia and South Sandwich archipelagoes are sub-Antarctic islands that fall within the scope of SCAR (Scientific Committee on Antarctic Research).

Conservation of the environment for future generations as an obligation of the present is part of all cultures and has been evident in many social, legal and religious institutions. Nowadays conservation is a principle, unchallenged and universally accepted, in spite of the fact that, in practice, participants might deviate from it due to short-term considerations. Regulation of these short-term considerations is seen by Argentina as the basis for management and is at the core of our legislation. However, a description of the conservation and management framework requires an understanding of the developing nature of the regulatory body.

In 1812 a new method of processing seal skins was introduced in pelt factories increasing commercial interest in southern sealing. Despite efforts to regulate catches, Patagonian seals were depleted below commercial levels by 1825 .

In 1913 Chile proposed a Convention, to be agreed by Argentina, Brazil and Uruguay, to jointly regulate hunting and fishing in the southern seas. The impossibility of including the long-distance operators in this Convention meant that adherence to the Convention would act "against the signatories and to the benefit of the non-adhering".

In April 1924, the Argentine Secretary for cattle production, remarkable jurist and economist Dr José León Suárez presented to the League of Nations through its Committee of Experts for the Progressive Codification of International Law a proposal for the immediate establishment of uniform regulations for the exploitation of maritime industries. He suggested convening a Commission of Experts (from all interested governments) to draft such regulations through "successive consultations" (Suárez 1925).

The League of Nations Committee of Experts charged Dr Suárez to analyse and report back on "the feasibility of establishing, by international agreement, rules about the exploitation of marine riches", taking into account existing treaties and other international instruments. In preparing his report, Dr Suárez consulted with experts from several countries, and identified the main issues under discussion at that time. His report of the appalling situation and future of the marine resources was presented to the Committee in December 1925. In January 1926, it was presented - together with the Committee's recommendation on the urgent nature of the decisions to be made - to the Council of the League of Nations. Enshrined in this report is the idea that measures had to be taken with a view to imposing regulations on the free take of natural resources which had resulted in an open race, ignoring long term considerations (Suárez 1925).

The report also recognised the wider and long-term consequences of unregulated exploitation: “... particularly in the maritime fauna the biological solidarity, considered jointly within all species, is more effective than in the terrestrial fauna, the disappearance of some will cause an unbalance in their harmonies and fights for existence and the extinction of others". As early as 1926, it was accepted that conservation is an ecosystem issue that must be dealt with in an international and multidisciplinary frame.

In his report Dr Suárez clearly identified the issues involved in the regulation of the exploitation of marine resources. These were later formalised, described and modelled:

- The lack of international regulation will lead marine species to extinction.

- There is a growing need for food resources, in particular marine resources.

- The extinction of one species entails the risk of loss of balance in the ecosystem and the extinction of other species.

- Most species are migratory, with a distribution pattern that varies geographically and from year to year.

- The absence of international regulation pushes commercial companies to over-capitalise in order to take the largest possible share of a dwindling resource.

- Technological improvements break the balance between production and consumption of marine species.

- The authority derived from the existence of maritime jurisdictions (three miles at the time, which might be expanded) - is not enough to provide the type of regulatory frame needed.

- There is a need for the uniform regulation of "sea industries" which are "a food reserve of mankind", especially in the continental shelves and in Antarctic waters.

- There is a need to determine the most efficient method to survey and control the application of international regulations.

- Existing treaties are insufficient and could, at best, only 
delay the final extinction of resources. Most of these treaties might well represent an additional risk as not only they are limited both in membership and scope but also exclusively take into account "commercial interests and political reciprocities", thus leaving aside the "biological interest", a concept that is not separable from the "general economic interest".

- While the undeniable need to establish international regulation for the exploitation of the biological riches of the sea is new to jurists, the need is recognised by all who have an interest (scientific or commercial) in marine fauna.

- It is prudent to establish a technical commission with membership open to all interested governments. Within such a commission, the views of lawyers, scientists and the industry should be considered in the establishment of international regulations.

From 1931 onwards, whaling became a highly regulated operation but regulations were unable to prevent the further decline of the whale stocks.

The international developments in fisheries regulation followed the path of partial agreements, applying to a large number of fisheries agreements covering high seas and shared resources (limited to seals and whales in the southern seas) and the expansion of the jurisdiction and responsibilities of coastal states into maritime zones.

By the mid-1970s the problems of over-exploitation of demersal fish around the South Georgia islands were evident: after a period of rapid expansion in the 1960s and early 1970 s catches had substantially declined. This, together with the growing interest of the fishing industry in krill (Euphausia superba Dana, 1850), prompted the convening of a technical conference in 1976 .

The conference considered it difficult to provide for the rational administration of fisheries on the basis of the Anrarctic Treaty alone. As already recognised in Dr Suárez's report, fishing agreements cannot ensure conservation objectives. Political and economic considerations will pervade deliberations and eventually result in the depletion of stocks as seen in most of the world's fisheries. The conference highlighted the need for a specific legal, political and scientific framework within which measures could be developed and implemented.

In 1977 the Antarctic Treaty Consultative Meeting initiated a negotiating process which resulted in the adoption of the Convention for the Conservation of Antarctic Marine Living Resources (CCAMLR) in 1980 (CCAMLR 2005).

Argentina participated actively and welcomed the inception of the CCAMLR Convention, since CCAMLR elaborated and consolidated many of the principles and concepts that had evolved during the previous $50-60$ years; many of them can be traced back to the discussions in the League of Nations. This evolution has made CCAMLR an influential body developing many of the current ideas in the field of conservation. Besides these proactive characteristics it is also unique in that, as a part in the Antarctic Treaty System (ATS), it cannot act as the "owner" of the resources; it does not intend to optimise exploitation and it cannot generate fishing rights.

The theoretical approaches applied in the analyses of fishing strategies postulate that resources are either owned or open access. CCAMLR is a counterexample that proves that the dilemma is false: it is regarded as more advanced and more successful than most Regional Fisheries Management Organisations (RFMOs) and national administrations, without applying the tools derived from the existence of exclusive rights of access to the resources. CCAMLR established a geographical area following the concept of biological and oceanographic unity, and proposed the application of a uniform set of rules for the whole area, to "give effect to the objectives and principles set out in Article II of this Convention". To this end, the Commission "shall take full account of the recommendations and advice of the Scientific Committee".

CCAMLR's objectives spelt out completely and accurately those principles, giving also a basis for operational definitions, particularly Article II. These are as follows:

- Conservation applies not only to the resources, but is extended to the ecosystem as a whole.

- Conservation includes "rational", and not "optimal" use. In RFMOs' practice and in theoretical analyses of fisheries, optimal refers to the maximisation of economic benefits. Conservation as defined by the Convention is limited by the need to contribute to food security.

- Reference points are established, effectively ensuring conservation, independently of the discount rates used by different participants (Maximum Sustainable Yield and minimisation of the risk of changes).

- Restoration of populations depleted below those reference points is required.

- The rule of the special responsibility of the Flag State is included as a part of the system as - according to the Convention - the responsibility for investigating and sanctioning remains in the Flag State.

- The basic elements to be included in a system of international observation directed to "promote the objective and ensure observance of the provisions of this Convention", are established, thus effectively providing for boarding vessels in the high seas.

The principles include cooperation between Contracting Parties to implement the system; boarding and inspection by observers and inspectors designated by Members; procedures for Flag State prosecution and sanction and reporting the results to the Commission; targeting scientific research or harvesting vessels; designation by Members of observers and inspectors and reporting to the Members; and distinguishing two components in Members' contributions to the annual budget: a part defined on an equal sharing basis and a part calculated from the amount of living resources harvested.

Within CCAMLR, compliance and data collection fall within the responsibility of Flag States with the cooperation of all Members. Carrying an observer on board has become a standard requirement for vessels operating in the CCAMLR area, except for the krill fishery. In many instances a second observer is also included in the provisions of the relevant Conservation Measures (in general practice he or she is designated by the Flag State).

By its very nature, inspection creates a suite of legal and practical problems. The right of an inspector from any country to board a fishing or scientific research vessel in the CCAMLR area implied that the Flag State has to resign, at least to some extent, its authority over the vessel involved. This feat was achieved through an elaborate mechanism.

The inspector, while a national of the designating country, is not an inspector of that country but a "CCAMLR inspector designated by XX". Clear identification of this status is required and it is provided by a special document issued by the designating country in a CCAMLR-approved form. The vessel carrying a CCAMLR inspector must fly a CCAMLR-designed pennant and clearly inform the 
inspected vessel of the inspector's name (a special registry of designated inspectors is kept by the CCAMLR Secretariat) and its intention to inspect the vessel under the CCAMLR system of inspection.

The Convention provides its Parties with a mechanism for cooperation among different and even opposing legal systems, as long as the status quo is not modified. Smooth cooperation among countries at loggerheads both at global and local levels was made possible.

In this framework, the Chairman's Statement allows, under special circumstances, such as their pre-existence, the application of regulations based on ownership of the resources and always biased to the side of conservation.

Non-discrimination between Parties on any basis (e.g., history of catches, scientific efforts, etc.) makes CCAMLR provisions easily acceptable and internally legitimate for Parties and non-Parties.

In this way, CCAMLR's regulations are universally accepted because they are founded on incontrovertible principles. For example, the Catch Documentation Scheme has not been challenged in spite of the fact that it might be viewed as an unfair commercial practice which discriminates against some countries.

Thus, the CCAMLR conservation and management framework, founded on multilateral cooperation and Flag State responsibility, is not only fully applicable to the South Georgia and South Sandwich islands from a legal point of view but is also sound and effective enough to achieve the conservation objectives.

Argentina endorsed the CCAMLR Convention, contributed to the work of the Commission and Scientific Committee and developed its national legislation regarding its sub-Antarctic islands convinced that the appropriate management and conservation framework is the full application of the multilateral approach developed by CCAMLR. This approach is widely regarded as the most advanced conservation scheme for marine resources and its viability has been demonstrated.
The main Argentine legal instrument is Law 25263 (2000). Its main provisions are:

- definition of competences (Article 1)

- achievement of the objectives of the Convention (Article 2)

- recognition of the legal status of CCAMLR's regulations without delay (Article 3)

- definition of procedural matters regarding fishing within CCAMLR waters (Articles 4-8, 13-15 and 35-40)

- creation of the CCAMLR fund (Articles 9-11)

- obligation to carry a VMS in CCAMLR waters, at all times and without exceptions (Articles 16-18)

- sanctions for infringements (Articles 19-33)

- obligation to unload in Argentine ports (Article 34)

- reports from CCAMLR Observers and Inspectors, including sightings have legal standing (Article 41)

- provisions for research, scientific observation and inspection (Articles 42-45).

Within Argentinean national legislation, violation of CCAMLR's provisions — by Argentine-flagged vessels - is regarded as a serious infringement attracting heavier fines than those applied to similar situations outside the Convention area.

Argentina also applied in full the CCAMLR observation and inspection schemes, carried out port inspections and supported CCAMLR in all ways.

\section{REFERENCES}

Suárez, J.L. 1925: Rapport au Conselil de la Société des Nations. Questions Juridiques C 196. M. 70. 1927. V.I.

CCAMLR - Secretariat, 2005: Text of the Convention on the Conservation of Antarctic Marine Living Resources. CCAMLR Basic Documents, Hobart, Tasmania.

Law 25263 2000: Boletín Oficial de la República Argentina, $25 / 7 / 2000$.

(accepted 30 July 2007) 